\title{
On the direct estimation of mood change
}

\author{
RALF LINDMAN \\ Abo Adademi, Abo, Finland
}

\begin{abstract}
A scaling model is described that allows mood variation to be assessed from direct estimates of change, for given dimensions of mood. Possible applications are, for instance, psychopharmacological experiments where a natural reference state may not exist or lengthy series of observations where the invariance of a "standard state" is difficult to control. An experiment was conducted to test the interdimensional consistency of scale values obtained by the proposed model for alcohol-induced changes in tension state and euphoria.
\end{abstract}

The problems of measurement involved in the mapping of "mood" are rather more complex than the common use of mood-adjective checklists might suggest, from the point of view of qualitative as well as quantitative variation, and some of the traditional assumptions underlying their use have been criticized, for example, with respect to best response scale format and appropriate psychometric model (Sjöberg, Svensson, \& Persson, 1979). The aim of the present paper is to propose a model that yields data more sensitive to time-dependent variation for predetermined dimensions of mood than do the usual estimates produced on 4- or 5-point scales anchored at a common standard state, such as "normal" or "as usual."

Increased precision is frequently desirable, for instance in psychopharmacological experiments in which mood is studied as a function of treatments and elapsed time in a repeated measures design, and the advantages of magnitude estimation in this respect were clearly demonstrated in some of the early studies on the subjective effects of alcohol (Ekman, Frankenhaeuser, Goldberg, Bjerver, Järpe, \& Myrsten, 1963; Ekman, Frankenhaeuser, Goldberg, Hagdahl, \& Myrsten, 1964; Myrsten, 1971). The invariance of the standard state is, however, often difficult to control. Sometimes a natural reference state may simply not exist, for instance due to pharmacological action, or it may be hard to define for other reasons. Problems of this kind could be avoided if the subjects were allowed to communicate their mood changes directly instead of making their estimates relative to a fixed standard on repeated occasions.

\section{MODEL}

If mood variation on a given dimension is studied at

The author is indebted to Hannes Eisler, at the University of Stockholm, for his helpful advice on Equation 3, and to Ann-Mari Stenhäll, who conducted the experiment while a student at Ảbo Akademi. Financial support was provided by the Finnish Foundation for Alcohol Studies, and the manuscript was completed in its present form while the author was a Fulbright Research Scholar at Florida State University, Tallahassee. The author's mailing address is: Department of Psychology, Åbo Akademi, Vårdbergsgatan 1, SF-20700 Ảbo 70, Finland. $\mathrm{n}$ points in time, to a fixed common standard, then ordinary magnitude estimation yields the time vector

$$
\mathbf{R}_{\mathbf{1}} / \mathbf{R}_{\mathrm{s}} \quad \mathbf{R}_{\mathbf{2}} / \mathbf{R}_{\mathrm{s}} \quad \cdots \quad \mathbf{R}_{\mathbf{n}} / \mathbf{R}_{\mathrm{s}},
$$

At each point in time $t(t=1,2, \cdots, n)$ the subject is instructed to estimate his current state relative to the fixed standard state, $\mathbf{R}_{\mathbf{s}}$, which has usually been assigned a number such as 10 or 100 . The components of the time vector are the scale values.

However, utilizing the subjective state of the subject at the beginning of experimental treatment, that is, the baseline state, as his first standard, $R_{\mathbf{0}}$, his first estimate, $R_{1}$, may as well be defined relative to $R_{0}$ as to any arbitrary $R_{s}$. Thus, assigning to $R_{0}$ the value 100 , the first estimate $(t=1)$ will assume the form of a simple percentage: $R_{1} / 100$. At the time of the next estimation $(t=2)$, the subject is asked to consider $R_{1}$ his current standard, which is again assigned the value 100: the resulting estimate $\mathbf{R}_{\mathbf{2}} / \mathbf{R}_{\mathbf{1}}$ will again be expressed as a percentage. Updating the standard successively and resetting it at 100 every time, a time vector will be obtained, the components of which indicate percentage changes

$$
\begin{array}{lllll}
\mathbf{R}_{1} / \mathbf{R}_{\mathbf{0}} & \mathbf{R}_{\mathbf{2}} / \mathbf{R}_{\mathbf{1}} & \mathbf{R}_{3} / \mathbf{R}_{\mathbf{2}} & \cdots & \mathbf{R}_{\mathbf{n}} / \mathbf{R}_{\mathbf{n}-\mathbf{1}} .
\end{array}
$$

These data may be of immediate interest, for instance in trend or profile analyses. It is, however, also possible to transform the data into progressive change relative to a common standard, for example, $\mathbf{R}_{\mathbf{0}}$. Assuming that the requirements for ratio scale data are met, the elements can be multiplied, yielding the time vector

$$
\begin{gathered}
\frac{R_{1}}{R_{0}} \frac{R_{2}}{R_{1}} \cdot \frac{R_{1}}{R_{0}}=\frac{R_{2}}{R_{0}} \quad \frac{R_{3}}{R_{2}} \cdot \frac{R_{2}}{R_{0}}=\frac{R_{3}}{R_{2}} \cdot \frac{R_{2}}{R_{1}} \cdot \frac{R_{1}}{R_{0}}=\frac{R_{3}}{R_{0}} \\
\cdots \frac{R_{n}}{R_{n-1}} \cdot \frac{R_{n-1}}{R_{0}}=\frac{R_{n}}{R_{n-1}} \cdot \frac{R_{n-1}}{R_{n-2}} \cdots \frac{R_{1}}{R_{0}}=\frac{R_{n}}{R_{0}}, \quad(3)
\end{gathered}
$$

where $R_{0}$ can be regarded as unity, or a scale constant which can be omitted in denoting the scale values. 
It is obvious that statistical error will accumulate with increasing values of $n$. On the other hand, overall statistical error is likely to be reduced by the independence of potentially time-dependent variation of standards, and by the increased precision that can be achieved by the proposed method, provided that the estimates can be made with acceptable consistency. An experiment was conducted in order to investigate whether this premise was tenable.

\section{EXPERIMENT}

Owing to the absence of criterion data, the standard psychophysical approach was not feasible. A different approach to validating the procedure was suggested by the fact that, when stimuli are judged on magnitude scales defined by semantic opposites, a roughly reciprocal relation holds between the two sets of scale values (Eisler, 1962; Lilienthal, 1978; Shinn, 1974; Stevens \& Guirao, 1962; Stevens \& Harris, 1962; Torgerson, 1960). Assuming the generality of this relationship, scale values for mood opposites obtained by the direct estimation of change should also be reciprocally related. Two pairs of semantic opposites-tense/relaxed and elated/depressedwere investigated in the present experiment. Mood variation over time was achieved by alcohol treatment, and the adjectives were chosen so as to be representative of the most prevalently reported effects of alcohol on mood in normal social drinking contexts, transient tension reduction and euphoria (Freed, 1978; Russell \& Mehrabian, 1975), and, as their semantic opposites, the most frequently given antonyms of these adjectives.

\section{Method}

\section{Subjects and Design}

Among 45 male students who volunteered for a study of social drinking advertised at lectures and poster boards at Ảbo Akademi University, 26 nonsmoking moderate social drinkers were initially screened for participation. Of these, 21 selected subjects arrived for the first party; 2 failed to appear at the second party. The present report is based on data obtained from the remaining 19 subjects.

The subjects served as their own controls, each subject attending two parties. Nine subjects were served alcohol at their first party and only nonalcoholic beverages at their second party; the 10 other subjects were treated in reverse order. Alcohol and nonalcohol subjects were mixed at the four parties, which were also attended by volunteer female students in matching numbers.

\section{Procedure}

Preexperimental. On each of 2 days preceding the scheduled first party, each subject was asked to make a number of mood estimates. These were an initial estimate of mood to an "as usual" daily standard, and three estimates of mood change for each of nine dimensions: elated, energetic, talkative, tired, sociable, irritated, tense, relaxed, and depressed. This task made the subjects aware of the variations in their mood and acquainted them with the scaling technique. When they arrived at their first party, their estimates were checked by an experimenter, and their mood variations over the preexperimental period were discussed briefly. Apparent inconsistencies in the estimates were identified and pointed out by the experimenter, and the instructions for the mood change estimations were repeated. Before the first data on mood change were obtained in the party conditions, a first rating to the "as usual" was obtained for each of the four dimensions studied in the experiment (tense, relaxed, elated, depressed), to provide an initial reference state for each scale. On the rating form, these adjectives were interspersed with "'energetic," "talkative," "tired," "sociable," and "irritated," so that the point of the experiment would not be immediately obvious and expectancy effects could be minimized in this respect.

Direct estimation of mood change. The following instructions were given: "Imagine that you are asked to estimate your happiness at this moment. First try to recall how you felt at the time when you made your previous estimate and call that 100 per cent, like this

HAPPY \begin{tabular}{llll}
0 & $100 \%$ & $200 \%$ \\
\hline
\end{tabular}

\begin{abstract}
"Now, if you were to feel less happy than you did the last time, say only about half as happy, you would make a mark about halfway between $0 \%$ and $100 \%$ to indicate $50 \%$. But if you were to feel instead just a little happier, say for instance about $10 \%$ happier than you did the last time, then you would make your mark at about $110 \%$, and so on.

"This may all seem a bit strange at first, and perhaps difficult. If you have trouble, try first to become aware of whether you are feeling more happy or less happy. If you are feeling less happy, you should use the range to the left of $100 \%$. If you are feeling more happy, you should use the range to the right of $100 \%$. Remember, however happy or unhappy you felt the last time, it is still always called $100 \%$. Next, try to decide how much happier or less happy you feel at this moment, and try to make your mark as precisely as you can on the line so that it matches the way you feel now.

"If you feel like extending the line, you may do so, or else simply write your percentage into the margin."

The length of the line between $0 \%$ and $100 \%$ marks was $100 \mathrm{~mm}$ so that measured distance could easily be converted into ratios. The percentage change vector was then transformed into final scale values according to Equation 3, for each subject.
\end{abstract}

Party setting. Setting and company have been found to be important determinants of emotional adaptation in male social drinking (Freed, 1978; Kalin, 1972; Kalin, McClelland, \& Kahn, 1972; Lindman, 1982). Efforts were therefore made to provide a comfortable party setting by the use of subdued lights, dance music, and volunteer female students of psychology, who were invited to make up an even ratio of females to males on each occasion. A party lasted from 6 p.m. to 11 p.m., and 11 mood estimations were scheduled for each subject during this period, yielding $11 \times 19$ pairs of scale values for each dimension. The subjects were instructed to fill out their mood-estimation forms in the natural context of collecting drinks at the bar, at approximately 15 -min intervals during the first hour and at 30-min intervals for the last $4 \mathrm{~h}$. However, no attempts were made to enforce data collection beyond explaining the schedules to the subjects as they arrived, since the necessary surveillance and social interference could have adversely affected mood development. The final analyses were based on 236 observations, half of them obtained under alcohol conditions and half under control conditions.

Administration of alcohol. Drinks were served in 1:1 (vol/vol) proportions of orange juice and Finnish distilled spirit $(28 \%$ weight $/ 34 \% \mathrm{vol}$ ), individually prepared to provide each subject in the alcohol condition with a total dose of $0.9 \mathrm{~g} / \mathrm{kg}$ body weight pure ethanol. The total dose was subdivided into four drinks, which were served at approximately 15 -min intervals at the beginning of the party. Orange juice was served ad lib for the rest of the evening. The subjects taking part under the control conditions received doses of orange juice proportionate to their total fluid intake in the alcohol condition, at comparable times.

Blood alcohol levels. Blood samples were taken from the tip of 
the index finger into $0.25-\mathrm{ml}$ capillaries at 90,150 , and $285 \mathrm{~min}$ after the beginning of intake. The observed blood alcohol levels were $0.776 \pm 0.052,0.709 \pm 0.054$, and $0.276 \pm 0.040 \mathrm{~g} /$ liter (mean \pm standard errors).

\section{Results}

\section{Manipulation Checks}

Analysis of variance was used to evaluate the effects of the alcohol treatment and the order of treatments on mood. The data were the scale values for the tense and elated estimates made at 90 min after the beginning of intake, when the subjective effects of intoxication were assumed to be maximal and complete sets of data were available. The scale values had been transformed according to Equation 3, so that all were expressed in terms of change from baseline. Significantly reduced tension $[\mathrm{F}(1,36)=14.47, \mathrm{p}<.001]$ and increased elation $[\mathrm{F}(1,36)=11.74, \mathrm{p}<.01]$ were observed following alcohol treatment; both mood variables remained unaffected by the order in which the treatments had been administered. The mean tense and elated estimates observed under alcohol and control conditions are shown in Figure 1 as functions of time for the duration of the experiment.

\section{Interdimensional Consistency}

All estimates of change were first expressed in terms of a common baseline according to Equation 3. As the estimates were unaffected by treatment order, the data were pooled within alcohol and control conditions regardless of the order in which the treatments had been administered. The relation between the calculated scale values for tense and relaxed is shown in Figure 2. The plot suggests a reciprocal function, as predicted.

For both pairs of mood dimensions, correlations were calculated: (1) for the combined data from both the alcohol condition and the control condition, and (2) for alcohol-induced changes only, that is, from the alcohol condition alone. All correlations were statistically significant: For tense vs. relaxed, $r_{x y}=-0.62(N=236$, $\mathrm{p}<.001$; alcohol condition only, $\mathrm{r}_{\mathrm{xy}}=-0.76, \mathrm{~N}=$ $118, \mathrm{p}<.001)$ and for elated $\mathrm{vs}$. depressed, $\mathrm{r}_{\mathrm{xy}}=-0.24$ $\left(\mathrm{N}=236, \mathrm{p}<.01 ;\right.$ alcohol condition only, $\mathrm{r}_{\mathrm{xy}}=-0.29$,

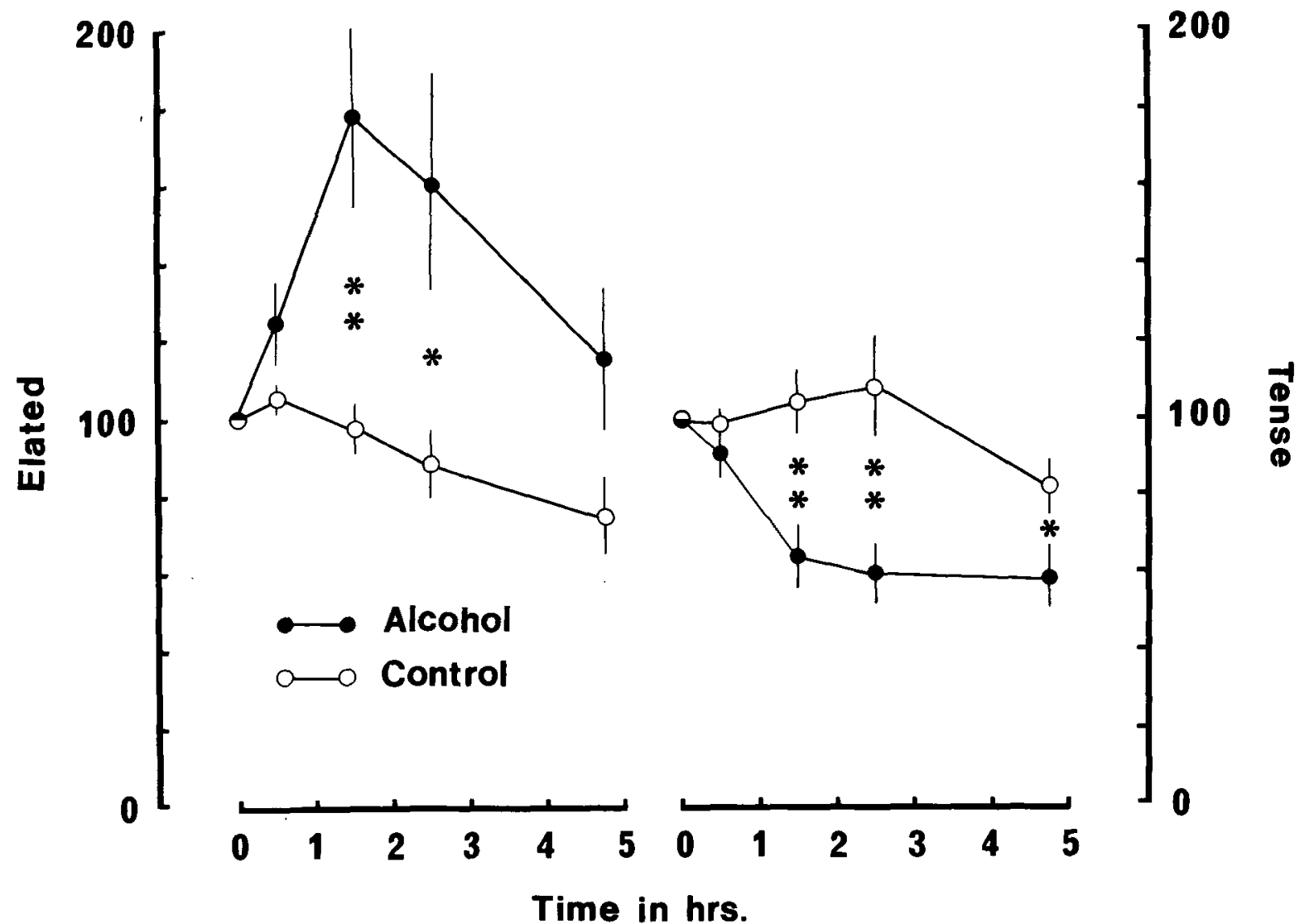

Figure 1. Mean scale values transformed to a common baseline for elation (left ordinate) and tension (right ordinate) as functions of time: with alcohol treatment (filled circles) and without (open circles). Two-tailed significance levels by $t$ tests for paired data of the differences between alcohol and control conditions: ${ }^{*} p<.05,{ }^{* *} p<.01$ (means and standard errors). 


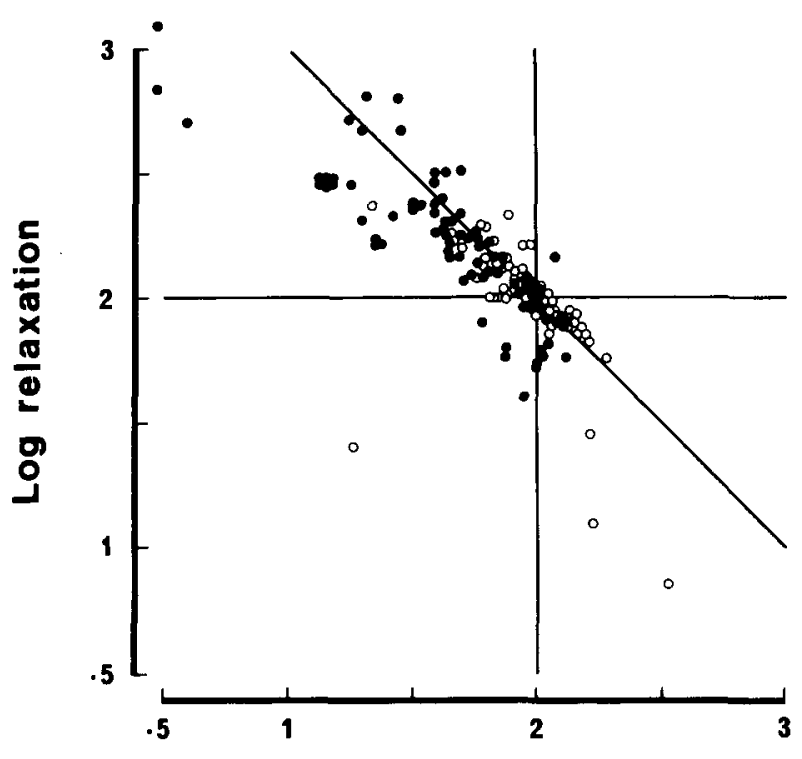

Log tension

Figure 2. Successive estimates of mood change transformed according to Equation 3 for tension and relaxation: with alcohol treatment (filled circles) and without (open circles).

$\mathrm{N}=118, \mathrm{p}<.01)$. The statistical significance of the observed correlations implies that the basic necessary condition for interdimensional consistency was met by both sets of scale values. Although only the estimates of tension versus relaxation resulted in a common variance large enough to suggest practical use. But since the weakness was apparent in only one of the pairs of dimensions studied, it can probably be attributed to the specific difficulties that might have been involved in the estimation of euphoria rather than to a failure of the scaling model.

\section{DISCUSSION}

These results are consistent with previous observations in natural drinking contexts with moderate social drinkers-that alcohol effects include transient euphoria and tension reduction (Freed, 1978; Lindman, 1982; Russell \& Mehrabian, 1975). Why, then, was elation more difficult to estimate consistently than tension?

Several explanations could be considered. First, the polarity and dimensionality of mood have been the subjects of considerable controversy (Sjöberg et al., 1979), whereas the evidence for the assumed underlying reciprocal relationship has been obtained on stimulus dimensions that are unequivocally bipolar in terms of physical units of measurement, for example, darkness/lightness (Torgerson, 1960), softness/loudness (Eisler, 1962; Stevens \& Guirao, 1962), and smoothness/roughness (Stevens \& Harris, 1962). Of abstract concepts, apparently only the importance versus unimportance of political office has been studied (Shinn, 1974). Although "depressed"' was the most frequently generated antonym of "elated," it can be argued that the assumed reciprocal relationship is more likely to hold for tense versus relaxed, since these adjectives are less equivocally opposites. Furthermore, consistent estimates of tension/relaxation could be easier to make because of the presence of physical cues, such as muscular tension. In the case of elation, cues might be quite subtle, or even nonexistent, and the influences of random factors correspondingly greater. Finally, when evaluating all of the present correlations, it should be noted that none of the subjects taking part in the experiment became either tense or depressed to any extent comparable to the alcohol-induced increases in elation and relaxation. Hence, compared with conditions in which subjects would experience the full range of variation for all four scales, the correlations may well be attenuated through the present restrictions in range. Although an experimental test cannot be justified on ethical grounds, results consistent with this argument were incidentally observed by Lindman (1982). In an experimental study of mood and drinking in social and solitary contexts, a short series of mood estimates $(n=3)$ indicated a scaling consistency of $\mathrm{r}=.92(\mathrm{p}<.001)$ for tense versus relaxed when the comparison included both an aversive condition-solitary drinking in impersonal surroundings-and a pleasure-inducing condition-social drinking in a natural drinking context.

The slight curvature that is evident in the data (Figure 2) may have contributed to lower correlations. Similar curvilinearities were previously observed by Torgerson (1960), Eisler (1962), and Shinn (1974), and it has been shown that curvature can be reduced by the application of a correcting factor (Eisler, 1962; Shinn, 1974). Easier judgment tasks and an open definition of the standard stimulus have been proposed as means to reduce curvature (Shinn, 1974). It could be argued that the reference point at $200 \%$ in the present graphical ratio estimation procedure may have introduced boundedness into the response scale, and possibly curvature (cf. Montgomery, 1975). The proposed scaling model is, of course, adaptable to any form of data based on ratio estimation of change, but the graphical method appears to be worth further development, mainly on grounds of expediency, since it was comparatively easy to teach and the subjects retained acceptable consistency even under moderate intoxication. Whether or not a linear relationship holds for these data as compared with numerical estimation data should be verified experimentally in future studies.

The most serious weakness associated with the application of Equation 3 is, however, that statistical error will accumulate towards the end of a series of reconstructed scale values. Estimates of the relative amounts of accumulated error can be calculated for different values of $n$, based on Hald (1952).

Denoting the terms of Equation 2 in a simpler form, the raw estimates may be written $x_{1}, x_{2}, \cdots, x_{n}$. Assuming any errors to be uncorrelated and random as to direc- 
tion and magnitude, and denoting by $y$ the reconstructed scale value based on the $n^{\text {th }}$ estimate produced by one subject, we have, generally,

$$
y=f\left(x_{1}, x_{2}, \ldots, x_{n}\right),
$$

or, more precisely, from Equation 3

$$
\mathrm{y}=\mathrm{x}_{1} \times \mathrm{x}_{2} \times \ldots \times \mathrm{x}_{\mathrm{n}} .
$$

Equation 5 may be written

$$
\ln y=\ln x_{1}+\ln x_{2}+\ldots+\ln x_{n} .
$$

Denoting by dy the estimated standard deviation at the $\mathrm{n}^{\text {th }}$ reconstructed scale value, we have, by partial logarithmic differentiation,

dy $=$

$$
\sqrt{\left[\left(\partial \mathrm{y} / \partial \mathrm{x}_{1}\right) \delta_{\mathrm{x}_{1}}\right]^{2}+\left[\left(\partial \mathrm{y} / \partial \mathrm{x}_{2}\right) \delta_{\mathrm{x}_{2}}\right]^{2}+\ldots+\left[\left(\partial \mathrm{y} / \partial \mathrm{x}_{\mathrm{n}}\right) \delta_{\mathrm{x}_{\mathrm{n}}}\right]^{2}}
$$

and

$$
\mathrm{dy} / \mathrm{y}=\sqrt{\left(\delta_{\mathrm{x}_{1}} / \mathrm{x}_{1}\right)^{2}+\left(\delta_{\mathrm{x}_{2}} / \mathbf{x}_{2}\right)^{2}+\ldots+\left(\delta_{\mathrm{x}_{\mathrm{n}}} / \mathrm{x}_{\mathrm{n}}\right)^{2}}
$$

The computational formula can hence be written simply

$$
\mathrm{dy}=\mathrm{y} \sum_{1}^{\mathrm{n}}\left(\delta_{\mathrm{x}} / \mathrm{x}\right)^{2}
$$

An initial error of $5 \%$ will thus entail a relative error of $11.2 \%$ at the 5 th reconstructed scale value and $16.6 \%$ at the 11 th. However, assuming an initial error of $10 \%$, the corresponding accumulated errors will be considerable: $22.4 \%$ and $33.2 \%$. It is obvious that any successful application of Equation 3 for a lengthy series of observations will be heavily dependent on the reliability of each estimate, and steps should be taken to ensure this.

As with magnitude estimation in general, naive subjects may find the task odd and confusing. Thorough familiarization with the procedure and preexperimental training were reasonably successful in the present experiment, and would seem advisable in future applications of the proposed model. Experimental designs should also provide for checks of the internal consistency of any transformed scale values before statistical analysis is attempted. If a number of mood dimensions are studied simultaneously, the same adjective could, for instance, be repeated twice. A comparison of the observed scale values would then entirely avoid the vexing complications involved in the definition of unequivocally bipolar dimensions of mood.

\section{REFERENCES}

EISLER, H. (1962). Empirical test of a model relating magnitude and category scales. Scandinavian Journal of Psychology, 3, 88-96.

Ekman, G., Frankenhaeuser, M., Goldberg, L., Bjerver, K., JARPE, G., MYRSTEN, A.-L. (1963). Effects of alcohol intake on subjective and objective variables over a five-hour period. Psychopharmacologia, 4, 28-38.

Ekman, G., Frankenhaeuser, M., Goldberg, L., Hagdahl, R., \& MYRSTEN, A.-L. (1964). Subjective and objective effects of alcohol as functions of dosage and time. Psychopharmacologia, 6, 399-409.

FreED, E. X. (1978). Alcohol and mood: An updated review. International Journal of the Addictions, 13, 173-200.

HALD, A. (1952). Statistical theory with engineering applications. New York: Wiley.

KALIN, R. (1972). Social drinking in different settings. In D. C. McClelland, W. N. Davis, R. Kalin, \& E. Wanner (Eds.), The drinking man (pp. 21-44). New York: Free Press.

Kalin, R., MCClelland, D. C., \& KaHN, M. (1972). The effects of male social drinking on fantasy. In D. C. McClelland, W. N. Davis, R. Kalin, \& E. Wanner (Eds.), The drinking man (pp. 3-20). New York: Free Press.

LILIENTHAL, M. G. (1978). Inverse magnitude estimation and reverse category estimation. Tests of ratio and interval scales. Dissertation Abstracts, 38, 5065-6B.

Lindman, R. (1982). Social and solitary drinking: Effects on consumption and mood in male social drinkers. Physiology \& Behavior, 28, 1093-1095.

Montgomery, H. (1975). Direct estimation: Effect of methodological factors on scale type. Scandinavian Journal of Psychology, 16, 19-29.

MYRSTEN, A.-L. (1971). Effects of alcohol on psychological functions: Experimental studies on nonalcoholic subjects. Reports from the Psychological Laboratories at the University of Stockholm, Supplement 7.

Russell, J. A., \& Mehrabian, A. (1975). The mediating role of emotions in alcohol use. Joumal of Studies on Alcohol, 36, 1508-1536.

ShinN, A. M., JR. (1974). Relations between scales. In H. M. Blalock, Jr. (Ed.), Measurement in the social sciences. Chicago: Aldine.

Suöberg, L., Svensson, E., \& Persson, L.-O. (1979). The measurement of mood. Scandinavian Joumal of Psychology, 20, 1-18.

Stevens, S. S., \& Guirao, M. (1962). Loudness, reciprocality, and partition scales. Joumal of the Acoustical Society of America, 34, 1466-1471.

StEvens, S. S., \& Harris, J. R. (1962). The scaling of subjective roughness and smoothness. Journal of Experimental Psychology, 64, 489-494.

TORGERSON, W. S. (1960). Quantitative judgment scales. In H. Gulliksen \& S. Messick (Eds.), Psychological scaling: Theory and applications. New York: Wiley.

(Manuscript received May 10, 1984. revision accepted for publication December 28, 1984.) 